\title{
PESQUISA DE AGLUTININAS ANTILEPTOSPIRA EM DIFERENTES GRUPOS PROFISSIONAIS NA CIDADE DE LONDRINA, PARANÁ
}

\author{
L.M. Vasconcelos, E.O. Cisalpino, M.N.R. Vieira e M.C. Koury
}

\begin{abstract}
Realizou-se um levantamento soroepidemiológico na cidade de Londrina - Paraná, para leptospirose, em 49 individuos não expostos a risco, 75 trabalhadores da limpeza pública, 55 indivíduos com atividade em ambiente hospitalar e 29 trabalhadores do Departamento de Água e Esgoto. Dos 208 soros analisados pela reação de soroaglutinação microscópica, 28,4\% apresentaram aglutininas antileptospira. A maior positividade foi encontrada nos soros dos trabalhadores da limpeza pública $(46,7 \%)$.
\end{abstract}

Palavras-chaves: Leptospira. Levantamento epidemiológico. Reação de soroaglutinação microscópica.

A leptospirose é uma zoonose, podendo o homem constituir-se em hospedeiro transitório das leptospiras. As leptospiroses podem resultar em doenças graves ou apenas subclínicas sugerindo, às vezes, quadros gripais ou resfriado, acometendo principalmente trabalhadores de esgoto, magarefes, agricultores e pescadores ${ }^{10}$.

No Brasil, vários trabalhos epidemiológicos foram realizados ${ }^{5}$. Em São Paulo ${ }^{12}$, encontrou-se em 200 trabalhadores do Departamento de Águas e Esgoto, uma positividade de $28,7 \%$ pela reação de soroaglutinação microscópica. De 372 soros de magarefes e inspetores federais do Departamento de Produtos Alimentícios de Origem Animal, 11 soros apresentaram positivos ${ }^{4}$. Na análise de 403 amostras de soro de trabalhadores da limpeza pública encontrou-se $2,9 \%$ de soros positivos ${ }^{6} \mathrm{e}$ em 79 soros de trabalhadores do serviço de água e esgoto de São Paulo, a positividade foi de 35,4\%7. A análise de 1766 soros de servidores da limpeza pública, funcionários do DAE, trabalhadores de cana-de-açucar e criadores de animais do Estado de São Paulo, 5,7\% dos soros foram positivos ${ }^{16}$. Um grande surto epidêmico de leptospirose ocorreu no Paraná, sendo que de 180 casos clínicos, 44 evoluíram para óbito ${ }^{13}$. Num estudo realizado em

\footnotetext{
Departamento de Microbiologia, Instituto de Ciências Biológicas, Universidade Federal de Minas Gerais. Belo Horizonte, MG, Brasil.

Endereço para correpondência: Profa. Matilde Cota Koury, Depto. de Microbiologia, ICB/UFMG, CP: 2486, 31271-970 Belo Horizonte, MG, Brasil.

Recebido para publicação em 09/09/92
}

94 trabalhadores de esgoto e 52 lixeiros, encontrouse $1,06 \%$ de positividade em trabalhadores de esgoto e $5,7 \%$ entre os lixeiros ${ }^{15}$. $\mathrm{Na}$ análise de aglutininas antileptospira em ferroviários na Itália encontrou-se uma prevalência de $10,38 \%$ de leptospirose infecção ${ }^{2}$.

O objetivo deste trabalho foi estudar a presença de aglutininas antileptospira em diferentes grupos profissionais na cidade de Londrina - Paraná.

\section{MATERIAL E MÉTODOS}

\section{Soros}

Examinou-se 208 amostras de soros de indivíduos residentes na cidade de Londrina, Paraná, Brasil. Coletou-se $8 \mathrm{ml}$ de sangue venoso de cada indivíduo. A população foi distribuída em:

Grupo I: 49 indivíduos, não expostos a risco, cuja atividade não implicava em contato com animais ou com material suspeito (professores, estudantes);

Grupo II: 75 trabalhadores da limpeza pública da cidade de Londrina;

Grupo III: 55 indivíduos que trabalhavam em ambiente hospitalar, (laboratorista);

Grupo IV: 29 trabalhadores do Departamento de Águas e Esgoto e limpadores de galerias.

\section{Antígenos}

Como antígenos foram utilizados 23 sorovares de leptospiras vivas: canicola Hond Utrecth IV; icterohaemorrhagiae RGA; grippotyphosa 
Vasconcelos LM, Cisalpino EO, Vieira MNR, Koury MC. Pesquisa de aglutininas antileptospira em diferentes grupos profissionais na cidade de Londrina, Paraná. Revista da Sociedade Brasileira de Medicina Tropical 25:251-255, out-dez, 1992.

Moskva V; autumnalis, Akiyami A; sentot, sejroe, M84; wolffi Horto; hardjo Hardjo prajitmo; panama, CZ214K; pomona Pomona; ballum, Mus 127; casteloni, Castelon 3, brastilava, Jez brastilava; australis, Ballico; shermani, LT821, pyrogenes, Salinem; javanica, Veldrat Bataviae 46; tarassovi, Perepelicim; bataviae, Van Tienen; brasiliensis, L966; andamana, CH11; butembo, Butembo e witicombi, Witicombi cultivadas em meio de Stuart ${ }^{17}$ durante 7 dias a $28^{\circ} \mathrm{C}$.

\section{Reação sorológica}

A pesquisa de aglutininas antileptospiras foi realizada pela reação de soroaglutinação microscópica (SAM)11. Como título final, considerou-se a maior diluição de soro que apresentou $50 \%$ de leptospiras aglutinadas. A reação foi considerada positiva a partir de 1:200.

\section{RESULTADOS}

$\mathrm{Na}$ análise dos soros pertencentes a indivíduos com diferentes atividades profissionais pela reação de SAM, obteve-se os resultados apresentados na Tabela 1. O grupo I (atividade considerada sem risco) apresentou $10,2 \%$ de positividade, enquanto que a maior positividade foi encontrada no grupo II (limpeza pública) 46,7\%. No total de 208 soros examinados $28,4 \%$ apresentaram reações positivas.

Os títulos obtidos na reação de SAM com diferentes sorovares de leptospiras estão apresentados

Tabela 1 - Resultado da reação de soroaglutinação microscópica (SAM) em 208 soros de individuos com diferentes atividades profissionais.

\begin{tabular}{lccc}
\hline \multirow{2}{*}{ Grupos } & \multicolumn{3}{c}{ S A M } \\
\cline { 2 - 4 } & $\begin{array}{c}\text { Positivo } \\
(\%)\end{array}$ & $\begin{array}{c}\text { Negativo } \\
(\%)\end{array}$ & $\begin{array}{c}\text { Total de } \\
\text { soros }\end{array}$ \\
\hline I $\begin{array}{l}\text { Sem risco } \\
\text { II } \begin{array}{l}\text { Limpeza pública } \\
\text { (lixeiros) }\end{array}\end{array}$ & $5(10,2)$ & $44(89,8)$ & 49 \\
III & $35(46,7)$ & $40(53,3)$ & 75 \\
IV $\begin{array}{l}\text { Traboratorista } \\
\quad \text { águas/esgoto de }\end{array}$ & $12(21,8)$ & $43(78,2)$ & 55 \\
\hline Total & $7(24,1)$ & $22(75,9)$ & 29 \\
\hline
\end{tabular}

na Tabela 2. No grupo I o título mais alto $(1: 1600)$ foi para sorovar panama e o sorovar prevalente foi javanica. No grupoII o título mais elevado (1:3200) foi para o sorovar panama. Os sorovare de maior ocorrência foram javanica e grippotyphosa. No grupo III, o título mais elevado (1:600) foi pąra os sorovares javanica, canicola e hardjo. O sorovar prevalente foi a javanica. No grupo IV o titulo mais alto foi de (1:600) para sorovar wolffi.

\section{DISCUSSÃO}

Observou-se uma alta incidệncia de sọros positivos, pela reação de SAM, nos indivíduos da cidade de Londrina. Em indivíduos considerados saudáveis, não expostos a risco, obteve-se uma positividade de $10,2 \%$ índice alto sugerindo que a infecção por leptospiras na população em geral é freqüente, sendo o microrganismo provavelmente muito disseminado entre os animaís. Esses dados concordam com os de Magaldi em Sao Paulo ${ }^{12}$ que detectou em 80 indivíduos saudáveis uma positividade de $12,5 \%$ e Amato Neto e $\mathrm{col}^{1}$ que encontraram $11,1 \%$ de positividade em 72 indivíduos saudáveis. Em Barbados, Demude e $\mathrm{col}^{8}$ observaram uma positividade de $15,0 \%$.

Nos indivíduos que apresentaram anticorpos antileptospira no grupo I, verificou-se que um era professor de inglês e havia se banhado em água de fonte não tratada e em sua residência possuia cães e gatos. O segundo indivíduo era viajante e esporadicamente participava de pescarias. O terceiro indivíduo era guarda de trânsito e freqüentemente entrava em contato com águas de rio. O quarto era escriturário e possuia cães e o quinto era eletricista, sem indício epidemiológico relacionado com contaminação com leptospiras.

O grupo II (lixeiros), foi a população que demonstrou mais alto grau de positividade $(46,7 \%)$ na amostra estudada. Este grupo foi o mais exposto a risco devido à própria natureza de suas atividades. Contribuiu ainda a situação sócio-econômica desses trabalhadores que vivem em condições precárias de higiene e alimentação . Em Curitiba, Romanholi encontrou, em 52 lixeiros, $5,7 \%$ de positividade ${ }^{15}$. Os sorovares prevalentes foram: icterohaemorrhagiae, pomona e canicola. Em São Paulo, em 316 indivíduos da mesma categoria profissional, Correa e col encontraram $3,1 \%$ de 
Vasconcelos LM, Cisalpino EO, Vieira MNR, Koury MC. Pesquisa de aglutininas antileptospira em diferentes grupos profissionais na cidade de Londrina, Paraná. Revista da Sociedade Brasileira de Medicina Tropical 25:251-255, out-dez, 1992.

Tabela 2 - Títulos obtidos na Reação de Soroaglutinação Microscópica (SAM) para diferentes sorovares de leptospira em soros de 208 indivíduos com diferentes atividades profissionais.

\begin{tabular}{|c|c|c|c|c|c|c|c|c|c|}
\hline \multirow[b]{2}{*}{$\begin{array}{l}\text { Sorovares de } \\
\text { Leptospiras }\end{array}$} & \multicolumn{2}{|c|}{ Grupo I } & \multicolumn{2}{|c|}{ Grupo II } & \multicolumn{2}{|c|}{ Grupo III } & \multicolumn{2}{|c|}{ Grupo IV } & \multirow[b]{2}{*}{ Total } \\
\hline & $\begin{array}{l}\mathrm{N}^{\circ} \text { rea- } \\
\text { ções po- } \\
\text { sitivas }\end{array}$ & $\begin{array}{l}\text { Títulos } \\
\text { SAM }\end{array}$ & $\begin{array}{l}\mathrm{N}^{0} \text { rea- } \\
\text { ções po- } \\
\text { sitivas }\end{array}$ & $\begin{array}{l}\text { Títulos } \\
\text { SAM }\end{array}$ & $\begin{array}{l}\mathrm{N}^{0} \text { rea- } \\
\text { ções po- } \\
\text { sitivas }\end{array}$ & $\begin{array}{l}\text { Títulos } \\
\text { SAM }\end{array}$ & $\begin{array}{c}\mathrm{N}^{0} \text { rea- } \\
\text { ções po- } \\
\text { sitivas }\end{array}$ & $\begin{array}{l}\text { Títulos } \\
\text { SAM }\end{array}$ & \\
\hline Javanica & 3 & $\begin{array}{l}400(1)^{*} \\
800(2)\end{array}$ & 9 & $\begin{array}{l}200(4) \\
400(2) \\
800(3)\end{array}$ & 5 & $\begin{array}{r}200(3) \\
400(1) \\
1600(1)\end{array}$ & 1 & $200(1)$ & 18 \\
\hline grippotyphosa & $\begin{array}{l}- \\
- \\
-\end{array}$ & $\begin{array}{l}- \\
-\end{array}$ & $\begin{array}{l}9 \\
- \\
-\end{array}$ & $\begin{array}{l}200(3) \\
400(4) \\
800(2)\end{array}$ & 3 & $\begin{array}{l}800(1) \\
400(2)\end{array}$ & 2 & $\begin{array}{l}200(1) \\
800(1)\end{array}$ & 14 \\
\hline wolffi & 1 & $400(1)$ & 6 & $\begin{array}{l}200(3) \\
400(3)\end{array}$ & & & 1 & $1600(1)$ & 8 \\
\hline panama & 2 & $\begin{array}{r}400(1) \\
1600(1)\end{array}$ & 5 & $\begin{array}{r}200(3) \\
800(1) \\
3200(1)\end{array}$ & 1 & $200(1)$ & 1 & $200(1)$ & 9 \\
\hline andamana & 1 & $200(1)$ & 6 & $\begin{array}{l}200(4) \\
400(1) \\
800(1)\end{array}$ & 4 & $\begin{array}{l}200(2) \\
400(1) \\
800(1)\end{array}$ & & & 11 \\
\hline icterohaemorrhagiae & & & 5 & $\begin{array}{r}200(1) \\
400(3) \\
1600(1)\end{array}$ & 1 & $200(1)$ & 1 & $400(1)$ & 7 \\
\hline canicola & & & 7 & $\begin{array}{r}200(3) \\
800(2) \\
1600(2)\end{array}$ & 1 & $1600(1)$ & 2 & $200(2)$ & 10 \\
\hline hardjo & 1 & $400(1)$ & 1 & $1600(1)$ & 1 & $1600(1)$ & 1 & $800(1)$ & 4 \\
\hline sejroe & - & - & 4 & $\begin{array}{l}200(2) \\
400(1) \\
800(1)\end{array}$ & 1 & $200(1)$ & 2 & $\begin{array}{l}400(1) \\
800(1)\end{array}$ & 7 \\
\hline bataviae & - & - & 3 & $\begin{array}{l}400(1) \\
800(2)\end{array}$ & 1 & $200(1)$ & 1 & $800(1)$ & 5 \\
\hline ballum & 2 & $\begin{array}{l}200(1) \\
400(1)\end{array}$ & - & - & 1 & $200(1)$ & - & - & 3 \\
\hline castelloni & - & - & 3 & $\begin{array}{l}400(2) \\
800(1)\end{array}$ & 1 & $400(1)$ & 2 & $\begin{array}{l}200(1) \\
800(1)\end{array}$ & 6 \\
\hline Progenes & - & - & 4 & $\begin{array}{l}200(1) \\
400(2) \\
800(1)\end{array}$ & 1 & $800(1)$ & - & - & 5 \\
\hline sentot & - & - & 4 & $400(4)$ & - & - & - & - & 4 \\
\hline australis & - & - & 2 & $\begin{array}{l}400(1) \\
800(1)\end{array}$ & - & - & 1 & $400(1)$ & 3 \\
\hline bratislava & 2 & $200(2)$ & 2 & $\begin{array}{r}800(1) \\
1600(1)\end{array}$ & - & - & - & - & 4 \\
\hline pomona & 1 & $400(1)$ & - & - & 1 & $200(1)$ & - & - & 2 \\
\hline hutembo & 1 & $800(1)$ & - & - & 1 & $400(1)$ & 1 & $200(1)$ & 3 \\
\hline shermani & - & - & 4 & $200(4)$ & - & - & - & - & 4 \\
\hline brasiliensis & - & - & 2 & $200(2)$ & - & - & - & - & 2 \\
\hline hiticombi & - & - & - & - & 1 & $200(1)$ & 1 & $200(1)$ & 2 \\
\hline autummalis & - & - & 2 & $\begin{array}{l}200(1) \\
400(1)\end{array}$ & - & - & - & - & 2 \\
\hline Earassovi & - & - & - & - & - & - & - & - & 0 \\
\hline Total & 14 & & 78 & & 24 & & 17 & & 133 \\
\hline
\end{tabular}

* ( ) $\mathrm{N}^{0}$ de soros que apresentaram o mesmo título 
Vasconcelos LM, Cisalpino EO, Vieira MNR, Koury MC. Pesquisa de aglutininas antileptospira em diferentes grupos profissionais na cidade de Londrina, Paraná. Revista da Sociedade Brasileira de Medicina Tropical 25:251-255, out-dez, 1992.

positividadepara o sorovar icterohaemorrhagiae . $^{6}$ Santa Rosa e col ${ }^{16}$ detectaram em 317 indivíduos $9,7 \%$ de positividade. Os autores relataram que essa positividade, relativamente baixa encontrada na população de lixeiros possivelmente se deva ao fato da exposição relativa desses trabalhadores, pois usavam luvas e botas. No entanto, em 103 trabalhadores da limpeza pública de Barbados, Demude e col detectaram $42,7 \%$ de positividade ${ }^{8}$.

No grupo III constituído de indivíduos com atividades em laboratórios, encontrou-se uma positividade de $21,8 \%$. Em 30 enfermeiras, Welsh e $\mathrm{col}^{18}$, no Vietnam, encontraram $17,0 \%$ de positividade. Em 25 empregados de laboratório, Cacchione e $\mathrm{col}^{3}$, na Argentina, detectaram uma positividade de $12,0 \%$. Osindivíduos com atividades em laboratórios constituem um grupo exposto a risco de contaminação, o que possivelmente está relacionado com a alta positividade encontrada nesse grupo III e nos empregados de laboratórios na Argentina $^{3}$ e enfermeiras do Vietnam ${ }^{18}$.

No grupo IV constituído de trabalhadores do setor de águas e esgoto a positividade foi de $24,1 \%$. Em São Paulo, encontrou-se uma positividade de $28,55 \%$ em 200 trabalhadores da mesma categoria ${ }^{12}$. Índices inferiores ao encontrado foram descritos em Porto Alegre por Edelweiss, que observou em 86 soros examinados, $2,3 \%$ de positivos ${ }^{9}$. Em Curitiba ${ }^{15}$, a positividade foi de $1,06 \%$, e em Belo Horizonte $^{14}$, de $1,47 \%$. Santa Rosa e col ${ }^{16}$ detectaram uma positividade de $0,5 \%$ na mesma categoria profissional. A alta positividade encontrada no grupo IV, trabalhadores do setor de água e esgoto, pode estar relacionada com as condicões higiênicas e de sanitarismo que condicionam o grau de exposição do homem e a distribuição da doença.

Neste trabalho, o resultado das análises dos soros dos indivíduos com diferentes atividades profissionais demonstra que a maior positividade para infecção por leptospira foi observada em lixeiros $(46,7 \%)$, cuja profissão os expõe a um maior risco de contaminação. Nos indivíduos do grupo I, cuja atividade foi considerada sem risco, observou-se uma positividade de $20,2 \%$. A presença de aglutininas nesse grupo pode ser explicada pela contaminação com leptospiras em atividades recreativas ou mesmo pelo contato com animais.

\section{SUMMARY}

Serum samples were obtained from 208 individuals in Londrina, Paraná, Brazil. The serum were analysed for leptospiral agglutinins by agglutination microscopic tests and $28.4 \%$ were positive. The highest positivity was found for the serum of garbage collector (46.7\%).

Key-words: Leptospira. Epidemiological study. Microscopic agglutination tests.

\section{REFERÊNCIAS BIBLIOGRÁFICAS}

1. Amato Neto V, Magaldi C, Correa MOA, Gomes MCO, Galiza I. Leptospirose canicola: Verificação em torno de um surto ocorrido em localidade próxima a São Paulo (capital). Revista do Instituto de Medicina Tropical de São Paulo 5:265-270, 1963.

2. Banfi E, Castagnari LL, Cinco M. Serosurvey of leptospira agglutinins among railway employees in the national railway compartments of Bologna and Venice. European Journal of Epidemiology 5:468473, 1989.

3. Cachione RA, Cascelli ES, Martinez ES. Encuesta serologica sobre leptospirosis humana en Argentina. Revista de la Associacion Argentina de Microbiologia 7:21-27, 1975.

4. Castro AFP, Santa Rosa CA, Almeida WF, Troise C. Pesquisa de aglutininas anti-leptospira entre magarefes em alguns municípios do Estado de São Paulo. Revista do Instituto de Medicina Tropical de São Paulo 8:287-290, 1966.

5. Correa MOA. Human leptospirosis in Brazil. International Journal of Zoonoses 2:1-9, 1975.

6. Correa MOA, Oliveira L, Martins JEC, Amato Neto $V$. Inquérito sorológico para leptospirose entre trabalhadores da limpeza pública da cidade de São Paulo. Revista Paulista de Medicina 70:102, 1967.

7. Cruz J, Trevisan S, Muniz JC, Litieri P, Câmara Ruf. Leptospiroses em trabalhadores da rede de esgotos de São Paulo. Revista do Departamento de Aguas e Esgoto 29:77-80, 1969.

8. Demude DF, Jones $\mathrm{Cl}$, White HSC, Myers DM. The problem of human leptospirose in Barbados. Transactions of the Royal Society of Tropical Medicine and Hygiene 73:169-177, 1979.

9. Edelweiss EL. Leptospiroses no Rio Grande do Sul. Revista do Instituto Adolfo Lutz 29/30:5-11, 1969/ 1970.

10. Faine S. Epidemiology, diagnosis and control of leptospirosis in man. Bulletin de l'Office Internacional des Epizooties 73:93- 99, 1970.

11. Galton MN, Mengers RW, Shotts Jr. EB, Nahmias 
Vasconcelos LM, Cisalpino EO, Vieira MNR, Koury MC. Pesquisa de aglutininas antileptospira em diferentes grupos profissionais na cidade de Londrina, Paraná. Revista da Sociedade Brasileira de Medicina Tropical 25:251-255, out-dez, 1992.

AJ, Heath Jr. CW. Leptospirosis - Epidemiology clinical manifestations in man and animals and methods in laboratory diagnosis. Public Helth Service - Washington U.S.A. Pub. 951, 1962.

12. Magaldi C. Contribuição à epidemiologia da leptospirose. Investigação em trabalhadores da Rede de Esgotos da cidade de São Paulo. Tese de Doutorado da Universidade de São Paulo, SP, 1962.

13. Miranda, NR. Doença de Weil no Paraná. Revista Médica do Paraná 15:229-234, 1946.

14. Nohmi N. Contribuição a epidemilogia de leptospiroses. Investigação em trabalhadores da Rede de Águas e Esgotos, armazéns, restaurantes e feiras livres da cidade de Belo Horizonte, MG. O Hospital 65:167-181, 1964.
15. Romanholi JA. Contribuição ao estudo da leptospirose na capital Paranaense, Curitiba. Tese de Doutorado da Universidade Católica do Paraná, Curitiba, PR, 1963.

16. Santarosa CA, Coscina AL, Castro AFP, Silva AS, Queiroz JC. Pesquisa de aglutininas anti leptospira em soros de trabalhadores de diversas profissões. Revista de Microbiologia 1:19-24, 1970.

17. Stuart RD. The preparation and use of a simple culture medium for leptospiral. Journal of Pathology and Bacteriology. 58:343- 349, 1946.

18. Welsh JD, Sulzer CR, Douglas H. Leptospiral seroreactors in the Mekong delta of South Vietnam. Southeast Asian Journal of Tropical Medice and Public Health 3:205-207, 1972. 